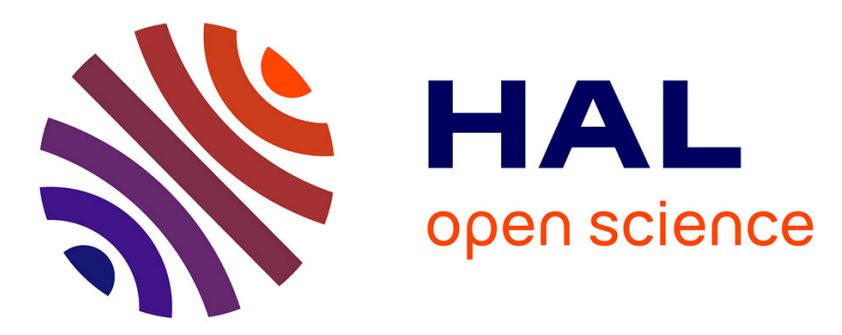

\title{
Threshold energy for atomic displacement in electron irradiated germanium
}

\author{
F. Poulin, J.C. Bourgoin
}

\section{To cite this version:}

F. Poulin, J.C. Bourgoin. Threshold energy for atomic displacement in electron irradiated germanium. Revue de Physique Appliquée, 1980, 15 (1), pp.15-19. 10.1051/rphysap:0198000150101500 . jpa00244691

\section{HAL Id: jpa-00244691 https://hal.science/jpa-00244691}

Submitted on 1 Jan 1980

HAL is a multi-disciplinary open access archive for the deposit and dissemination of scientific research documents, whether they are published or not. The documents may come from teaching and research institutions in France or abroad, or from public or private research centers.
L'archive ouverte pluridisciplinaire HAL, est destinée au dépôt et à la diffusion de documents scientifiques de niveau recherche, publiés ou non, émanant des établissements d'enseignement et de recherche français ou étrangers, des laboratoires publics ou privés. 


\title{
Threshold energy for atomic displacement in electron irradiated germanium $\left({ }^{*}\right)$
}

\author{
F. Poulin and J. C. Bourgoin \\ Groupe de Physique des Solides de l'E.N.S. (**), \\ Université Paris 7, Tour 23, 2, place Jussieu, 75221 Paris, France
}

\begin{abstract}
Résumé. - Du germanium de type $\mathrm{n}$ a été irradié avec des électrons d'énergie variable, de 0,5 à $3 \mathrm{MeV}$. En utilisant des mesures de capacité transitoire on a observé quatre pièges à porteurs majoritaires associés à des niveaux d'énergie à $0,27 \mathrm{eV}\left(E_{1}\right), 0,39 \mathrm{eV}\left(E_{2}\right), 0,35 \mathrm{eV}\left(E_{4}\right)$ et $0,32 \mathrm{eV}\left(E_{5}\right)$ en dessous de la bande de conduction. On a étudié les variations des taux d'introduction de ces pièges avec l'énergie d'irradiation. Ces variations correspondent à un seuil d'énergie pour le déplacement atomique de $20 \pm 5 \mathrm{eV}$ pour les pièges $E_{1}$ et $E_{2}$ et de $40 \pm 10 \mathrm{eV}$ pour les pièges $E_{4}$ et $E_{5}$. On en conclut que les pièges $E_{1}$ et $E_{2}$ sont dus à des défauts de type lacunaire ou interstitiel (association d'une lacune ou d'un interstitiel avec une impureté) alors que les pièges $E_{4}$ et $E_{5}$ sont dus à la dilacune.

Abstract. - n-type germanium has been irradiated with electrons of various energies in the range 0.5 to $3 \mathrm{MeV}$. Using transient capacitance measurements we observed four majority carrier traps associated with levels at $0.27 \mathrm{eV}$ $\left(E_{1}\right), 0.39 \mathrm{eV}\left(E_{2}\right), 0.35 \mathrm{eV}\left(E_{4}\right), 0.32 \mathrm{eV}\left(E_{5}\right)$ below the conduction band. We have studied the variations of the introduction rates of these traps with the energy of irradiation. These variations are found to correspond to a threshold energy for atomic displacement of $20 \pm 5 \mathrm{eV}$ for the $E_{1}$ and $E_{2}$ traps and of $40 \pm 10 \mathrm{eV}$ for the $E_{4}$ and $E_{5}$ traps. It is concluded that the $E_{1}$ and $E_{2}$ traps are associated with vacancy-or interstitial-type defects (association of a vacancy or of an interstitial with an impurity) while the $E_{4}$ and $E_{5}$ traps are associated with the divacancy.
\end{abstract}

1. Introduction. - It has been shown recently that transient capacitance techniques can provide useful informations on point defects in germanium [1], where other spectroscopic techniques such as electron paramagnetic resonance have apparently failed. Using Deep Level Transient Spectroscopy (DLTS) [2], two electron traps (labelled $E_{1}$ and $E_{2}$ ) and one hole trap $\left(H_{1}\right)$ have been detected in n-type germanium irradiated with $1 \mathrm{MeV}$ electrons, and the corresponding energy levels and cross-sections for carrier capture estimated [1].

How can the defects responsible for these traps be identified ? A possible way to distinguish intrinsic defects (vacancy, interstitial, divacancy) from complexes (association of intrinsic defects with impurities) is to study the variation of the introduction rates of the various traps observed versus the nature and the concentration of the impurities. A possible way to distinguish intrinsic or complex defects involving one vacancy or one interstitial from defects involving a divacancy is to study the variation of the trap introduction rates versus the energy of irradiation. Indeed,

$\left(^{*}\right)$ Conférence présentée au Congrès de la Société Française de Physique (Toulouse, 25-30 juin 1979).

(**) Laboratoire associé au C.N.R.S. when the energy $T$ transmitted by one energetic electron is such that $T_{\mathrm{d}}<T<2 T_{\mathrm{d}}\left(T_{\mathrm{d}}\right.$ is the threshold energy for atomic displacement i.e. the minimum energy which is required to produce a vacancyinterstitial pair) then only vacancy- or interstitialtype defects are created; when $T \geqslant 2 T_{\mathrm{d}}$ the displacement of two neighbouring atoms can occur with a non-negligible probability and divacancy-type defects are produced, with a threshold energy $\sim 2 T d$. This has been verified in electron irradiated silicon : the threshold energies for the vacancy and the divacancy have been measured and found to be $21 \mathrm{eV}$ and $42 \mathrm{eV}$ respectively [3].

The aim of this communication is to describe an attempt to determine the threshold energy of each of the traps produced by electron irradiation, by measuring their creation rates versus the energy of irradiation, in order to distinguish between vacancy (or interstitial) type defects and divacancy-type defects. We note that the transient capacitance techniques are particularly well adapted for the determination of a threshold energv because : (i) the measurements are performed in a depth of typically few microns in which the electron energy losses can be neglected (this is not the case when conductivity measurements are used, which require samples having a thickness of at 
least $100 \mu \mathrm{m}$ ); (ii) the results are not perturbed by surface effects (this can be the case when luminescence or conductivity techniques are used); (iii) the capacitance techniques provide the threshold energy of each defect, and not of the total defect concentration (conductivity measurements give only the concentration of all the electrical active defects).

2. Experimental. - The samples studied are $\mathrm{p}^{+}-\mathrm{n}$ (commercial OAP12) diodes having a donor concentration varying from 8.3 to $1.7 \times 10^{12} \mathrm{~cm}^{-3}$. The nature of the donor atom is unknown. Most of the diodes exhibit an abrupt junction, as illustrated by the fact that their capacitance-voltage $C(V)$ characteristics are such that $C^{-2}$ is linear with $V$, while few others exhibit a cube-root capacitance law indicating an abrupt junction followed by a linearly graded concentration. In this last case the carrier concentration $N_{\mathrm{D}}(W)$ which we used to calculate the defect concentration is the concentration at the depth $W(V)$ of the space charge region corresponding to the applied reverse bias $V$.

The diodes are irradiated at room temperature, with a electron beam intensity of $\sim 0.1 \mu \mathrm{A} \mathrm{cm}{ }^{-2}$ in order to introduce a negligible increase of the temperature. The electron beam is scanned in order to insure a homogeneous irradiation. The energy of irradiation ranges from $0.5 \mathrm{MeV}$ to $3 \mathrm{MeV}$. The doses range from $10^{15} \mathrm{~cm}^{-2}$ to $2 \times 10^{16} \mathrm{~cm}^{-2}$; they are chosen in such a way that the total concentration of traps introduced is of the same order of magnitude for all the irradiations.

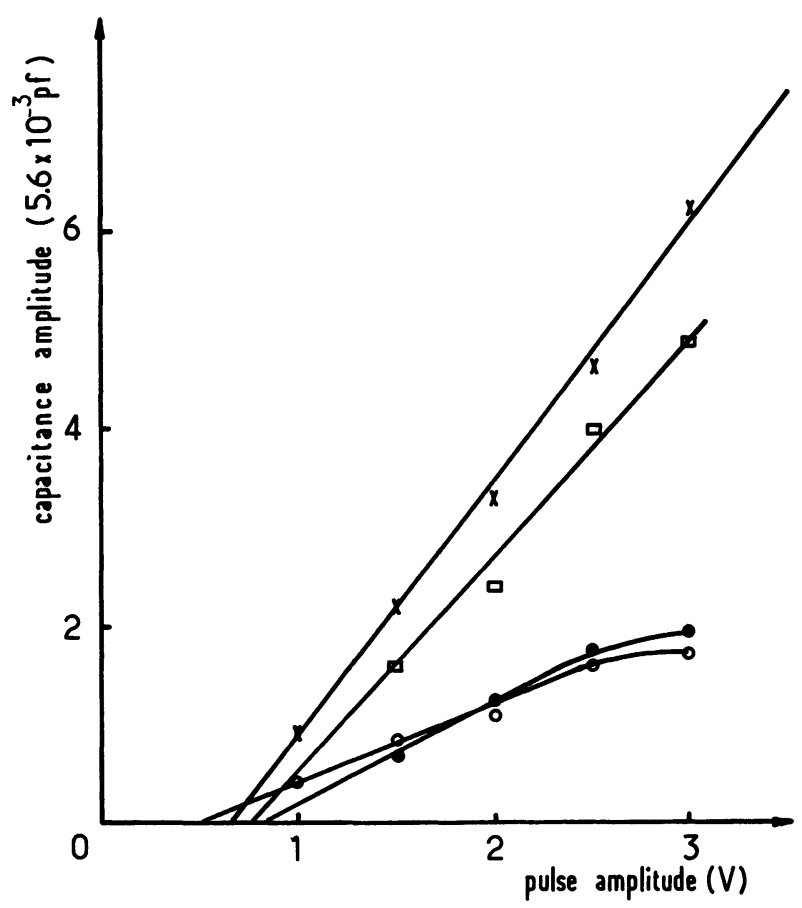

Fig. 1. - Amplitude of the DLTS signal versus the amplitude of the pulse applied for the four traps $E_{1}(0), E_{2}(\times), E_{4}(\square), E_{5}(0)$ in a diode irradiated at $1.6 \mathrm{MeV}$ with a dose of $10^{15}$ electrons $\mathrm{cm}^{-2}$ biased at $3.5 \mathrm{~V}$. The rate window is $14.4 \mathrm{~ms}$, the pulse width $100 \mu \mathrm{s}$ and the repetition rate $50 \mathrm{~ms}$.
The transient capacitance signal is recorded with a capacitance bridge (Booton model $72 \mathrm{~A}$ ) and analyzed with the help of two boxcars (Brookdeal model 9415). The positions of the energy levels $E_{\mathrm{T}}$ of the traps for majority carriers in the forbidden gap are determined using a method introduced by D. Pons [4]. For a given reverse bias, the amplitude $\Delta C$ of the capacitance transient is recorded versus the amplitude $\Delta V$ of the pulse applied to produce this transient (Fig. 1) and the energy level $E_{\mathrm{T}}$ is computed from the extrapolation $\Delta V_{0}$ of the curve $\Delta C(\Delta V)$ for $\Delta C=0$, using the fact that this threshold $\Delta V_{0}$ is related to the depths at which $E_{\mathrm{T}}$ crosses the Fermi level in the equilibrium conditions (with the reverse bias $V$ ) and when the traps are half-filled by the pulse $\Delta V$.

3. Experimental results. - We limited the present study to the majority (electron) carrier traps. A typical DLTS spectrum for irradiation at low energy (see Fig. $2 a$ ) exhibits the $E_{1}$ and $E_{2}$ traps in agreement with ref. [1]. When the energy of irradiation increases, two new traps, which we labelled $E_{4}$ and $E_{5}$, appear. As shown in figure $2 c$, the traps $E_{2}, E_{4}$ and $E_{5}$ are difficult to resolve and as a result, in most cases, the accuracy on the concentration of the traps $E_{4}$ and $E_{5}$ is low. In addition to these four traps another trap (labelled $E_{3}$ ) has been observed (Fig. $2 b$ ). Because it is only present in few particular cases (for the following irradiations : $2 \times 10^{15} \mathrm{~cm}^{-3}$ at $2 \mathrm{MeV}$ and

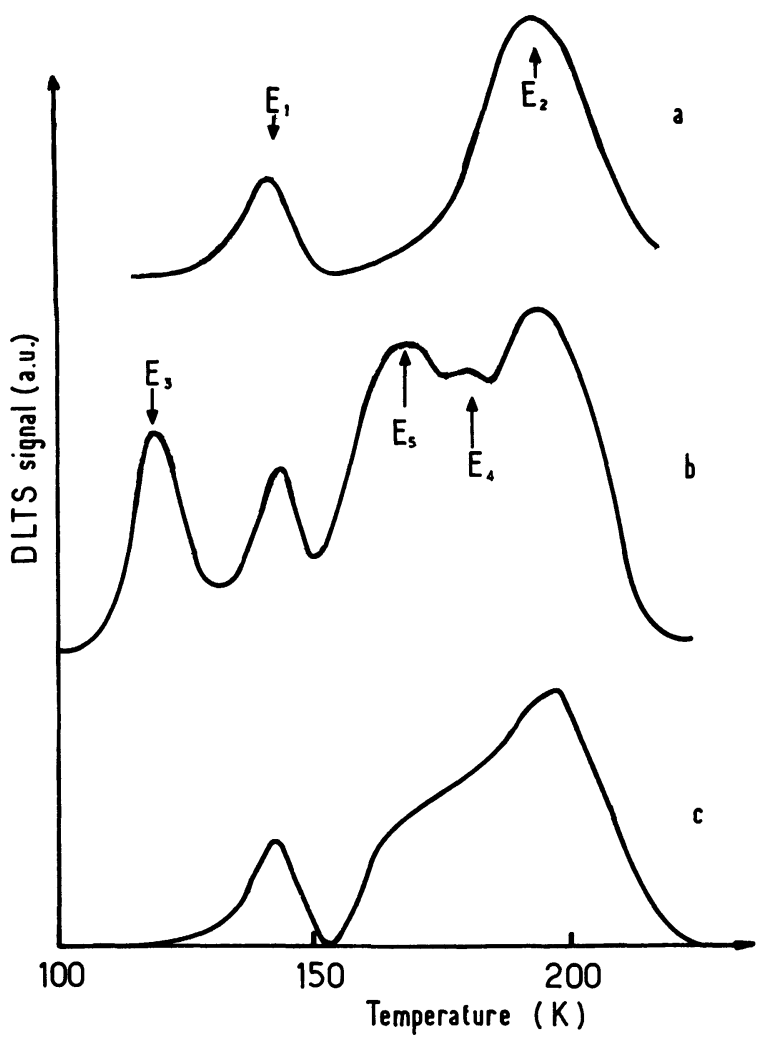

Fig. 2. - Typical DLTS spectra recorded in diodes irradiated at $0.54 \mathrm{MeV}, 10^{16} \mathrm{~cm}^{-2}(a), 2 \mathrm{MeV}, 2 \times 10^{15} \mathrm{~cm}^{-2}(b)$ and $2.5 \mathrm{MeV}$, $1.6 \times 10^{15} \mathrm{~cm}^{-2}(c)$. The rate window is $6.9 \mathrm{~ms}$. 
Table I. - Concentrations $N_{\mathrm{T} i}\left(\mathrm{~cm}^{-3}\right)$ and defect introduction rates $R_{i}\left(\mathrm{~cm}^{-1}\right)$ of the majority carrier traps observed after irradiation $(i=1,2,4,5)$ with a dose of electrons $\varphi\left(\mathrm{cm}^{-2}\right)$ at the energy $E(\mathrm{MeV})$. The sign * indicates that the accuracy on $\Delta V_{0}$ was too small to allow the calculation of the trap concentrations.

\begin{tabular}{|c|c|c|c|c|c|c|c|c|c|c|c|c|}
\hline Diode & 15 & 1 & 18 & 12 & 7 & & 19 & 13 & 9 & 17 & 10 & 16 \\
\hline $\begin{array}{l}E \\
\varphi\end{array}$ & $\begin{array}{c}0.54 \\
1.0 \times 10^{16}\end{array}$ & $\begin{array}{c}0.60 \\
2.0 \times 10^{16}\end{array}$ & 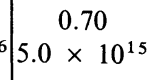 & $\begin{array}{c}0.82 \\
1.4 \times 10^{15}\end{array}$ & $5=\begin{array}{c}1.00 \\
2.0 \times 10^{15}\end{array}$ & & $\begin{array}{l}1.50 \\
\times 10^{15}\end{array}$ & $5 \begin{array}{c}1.61 \\
1.0 \times 10^{15}\end{array}$ & $\begin{array}{c}2.00 \\
2.4 \times 10^{15}\end{array}$ & $\left|\begin{array}{c}2.00 \\
2.0 \times 10^{15}\end{array}\right|$ & $\left|\begin{array}{c}2.48 \\
1.6 \times 10^{15}\end{array}\right|$ & $s=\begin{array}{c}2.90 \\
2.0 \times 10^{15}\end{array}$ \\
\hline $\begin{array}{l}N_{\mathrm{T} 1} \\
N_{\mathrm{T} 2} \\
N_{\mathrm{T} 4} \\
N_{\mathrm{T} 5}\end{array}$ & $\begin{array}{c}6.9 \times 10^{9} \\
1.6 \times 10^{10} \\
0 \\
0\end{array}$ & {$\left[\begin{array}{c}1.3 \times 10^{10} \\
5.6 \times 10^{10} \\
6.5 \times 10^{10} \\
*\end{array}\right.$} & $\begin{array}{c}* \\
* \\
4.610^{10} \\
* \\
*\end{array}$ & $\mid \begin{array}{l}5.7 \times 10^{9} \\
1.7 \times 10^{10} \\
1.5 \times 10^{10} \\
1.1 \times 10^{10}\end{array}$ & {$\left[\begin{array}{l}1.2 \times 10^{10} \\
2.7 \times 10^{10} \\
1.4 \times 10^{10} \\
3.3 \times 10^{9}\end{array}\right.$} & $\begin{array}{l}2.1 \\
1.2 \\
1.1\end{array}$ & $\begin{array}{l}* \\
\times 10^{11} \\
\times 10^{12} \\
\times 10^{12}\end{array}$ & $2 \begin{array}{l}6.1 \times 10^{9} \\
3.7 \times 10^{10} \\
3.0 \times 10^{10} \\
1.8 \times 10^{10}\end{array}$ & 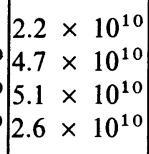 & $\begin{array}{l}2.5 \times 10^{10} \\
9.1 \times 10^{10} \\
9.3 \times 10^{10} \\
1.1 \times 10^{11}\end{array}$ & $\mid \begin{array}{c}* \\
6.7 \times 10^{10} \\
6.5 \times 10^{10} \\
5.4 \times 10^{10}\end{array}$ & $\mid \begin{array}{c}* \\
5.5 \times 10^{10} \\
8.8 \times 10^{10} \\
1.1 \times 10^{11}\end{array}$ \\
\hline $\begin{array}{l}R_{1} \\
R_{2} \\
R_{4} \\
R_{5}\end{array}$ & $\mid \begin{array}{c}6.9 \times 10^{-7} \\
1.6 \times 10^{-6} \\
0 \\
0\end{array}$ & $\begin{array}{c}6.6 \times 10^{-7} \\
2.8 \times 10^{-6} \\
3.2 \times 10^{-6} \\
*\end{array}$ & $6 \begin{array}{c}* \\
9.10^{-6} \\
* \\
*\end{array}$ & {$\left[\begin{array}{l}4.1 \times 10^{-6} \\
1.2 \times 10^{-5} \\
1.1 \times 10^{-5} \\
7.5 \times 10^{-6}\end{array}\right.$} & $5\left(\begin{array}{l}6.1 \times 10^{-6} \\
1.3 \times 10^{-5} \\
7.1 \times 10^{-6} \\
2.9 \times 10^{-6}\end{array}\right.$ & $\mid \begin{array}{l}6.8 \\
3.9 \\
3.6\end{array}$ & $\begin{array}{l}* \\
\times 10^{-5} \\
\times 10^{-4} \\
\times 10^{-4}\end{array}$ & $\begin{array}{l}6.2 \times 10^{-6} \\
3.3 \times 10^{-5} \\
3.0 \times 10^{-5} \\
1.2 \times 10^{-5}\end{array}$ & $\begin{array}{l}8.9 \times 10^{-6} \\
1.9 \times 10^{-5} \\
2.1 \times 10^{-5} \\
1.4 \times 10^{-5}\end{array}$ & $\begin{array}{l}1.3 \times 10^{-5} \\
4.6 \times 10^{-5} \\
4.6 \times 10^{-5} \\
5.7 \times 10^{-5}\end{array}$ & $\mid \begin{array}{c}* \\
4.2 \times 10^{-5} \\
3.9 \times 10^{-5} \\
3.3 \times 10^{-5}\end{array}$ & \begin{tabular}{c|c}
${ }^{*}$ \\
$5.8 \times 10^{-5}$ \\
5 \\
$4.4 \times 10^{-5}$ \\
$5.9 \times 10^{-5}$
\end{tabular} \\
\hline
\end{tabular}

$5 \times 10^{15} \mathrm{~cm}^{-2}$ at $0.7 \mathrm{MeV}$ ) this trap has not yet been studied.

The concentrations $N_{\mathrm{T}}$ and the introduction rates $R$ (defect concentration divided by electron dose) of all these traps are given in table 1 . The energy level positions of the traps have been calculated from the results obtained with diodes which allow to obtain a good accuracy on $\Delta V_{0}$ and exhibit a linear $C^{-2}(V)$ characteristics. They are : $E_{\mathrm{c}}-0.27 \pm 0.03 \mathrm{eV}\left(E_{1}\right)$, $E_{\mathrm{c}}-0.39 \pm 0.02 \mathrm{eV}\left(E_{2}\right), E_{\mathrm{c}}-0.35 \pm 0.02 \mathrm{eV}\left(E_{4}\right)$ and $E_{\mathrm{c}}-0.32 \pm 0.04 \mathrm{eV}\left(E_{5}\right)$. The signatures of these traps (variation of the logarithm of the emission rate versus $T^{-1}$ ) as well as their cross-sections for electron trapping will be given elsewhere.

4. Discussion. - The variations of the introduction rates versus the electron energy, for the traps $E_{1}, E_{2}$, $E_{4}$ and $E_{5}$, have been compared to the theoretical variations, calculated for various values of the threshold energy (for a description of such calculation see for instance ref. [5]). Since the defect concentration observed at room temperature is only propor-

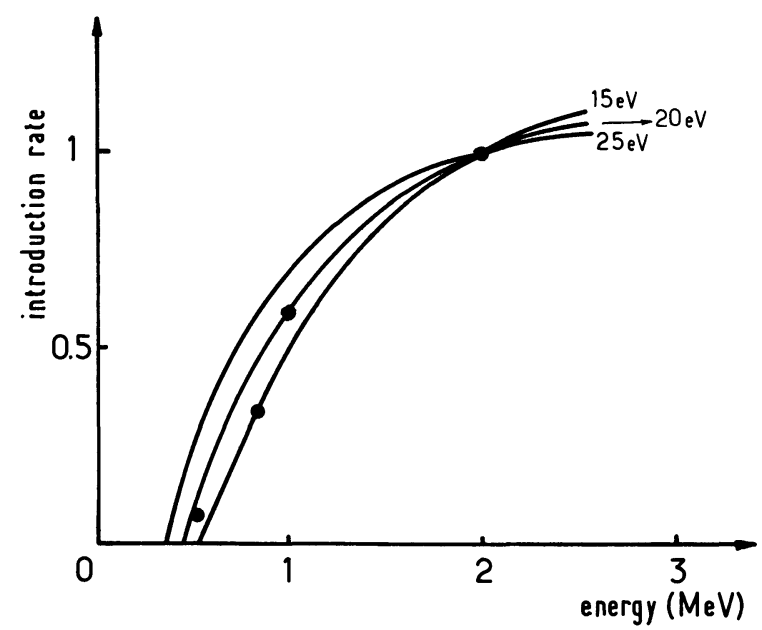

Fig. 3. - Variation of the $E_{1}$ trap introduction rate, normalized at $1 \mathrm{MeV}$, versus electron energy and comparison with theoretical curves calculated for various threshold energies. tional to the intrinsic defects created, because they are the result of vacancy or interstitial migration followed by their recombination or their association with impurities, these rates are normalized at a given energy in order to do this comparison. The results are given in figures 3-6 : the traps $E_{1}$ and $E_{2}$ appear to correspond to a threshold $T d=20 \pm 5 \mathrm{eV}$ (Figs. 3 and 4$)$; the traps $E_{4}$ and $E_{5}$ to a threshold of $40 \pm 10 \mathrm{eV}$ (Figs. 5 and 6 ).

The lower value of the threshold we observed $T d=20 \pm 5 \mathrm{eV}$ corresponds to the threshold for vacancy-interstitial pair production. This value is in agreement with previously published results which range from 13 to $23 \mathrm{eV}$ [6]. The traps $E_{1}$ and $E_{2}$ are therefore associated with defects involving a vacancy or an interstitial. Indeed, vacancies and interstitials are presumably mobile at room temperature in n-type germanium; an annealing stage is observed at $65 \mathrm{~K}$ which is attributed to the recombination of vacancy-interstitial pairs, through the mobility of the interstitial [7] ; in highly doped material another annealing stage is observed at $35 \mathrm{~K}$ also attributed

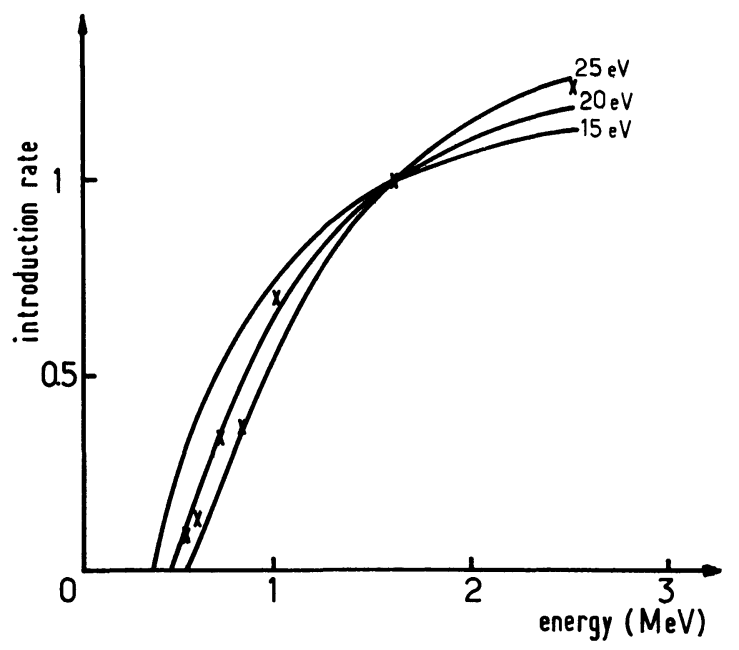

Fig. 4. - Variation of the $E_{2}$ trap introduction rate, normalized at $1.6 \mathrm{MeV}$, versus electron energy and comparison with theoretical curves calculated for various threshold energies. 


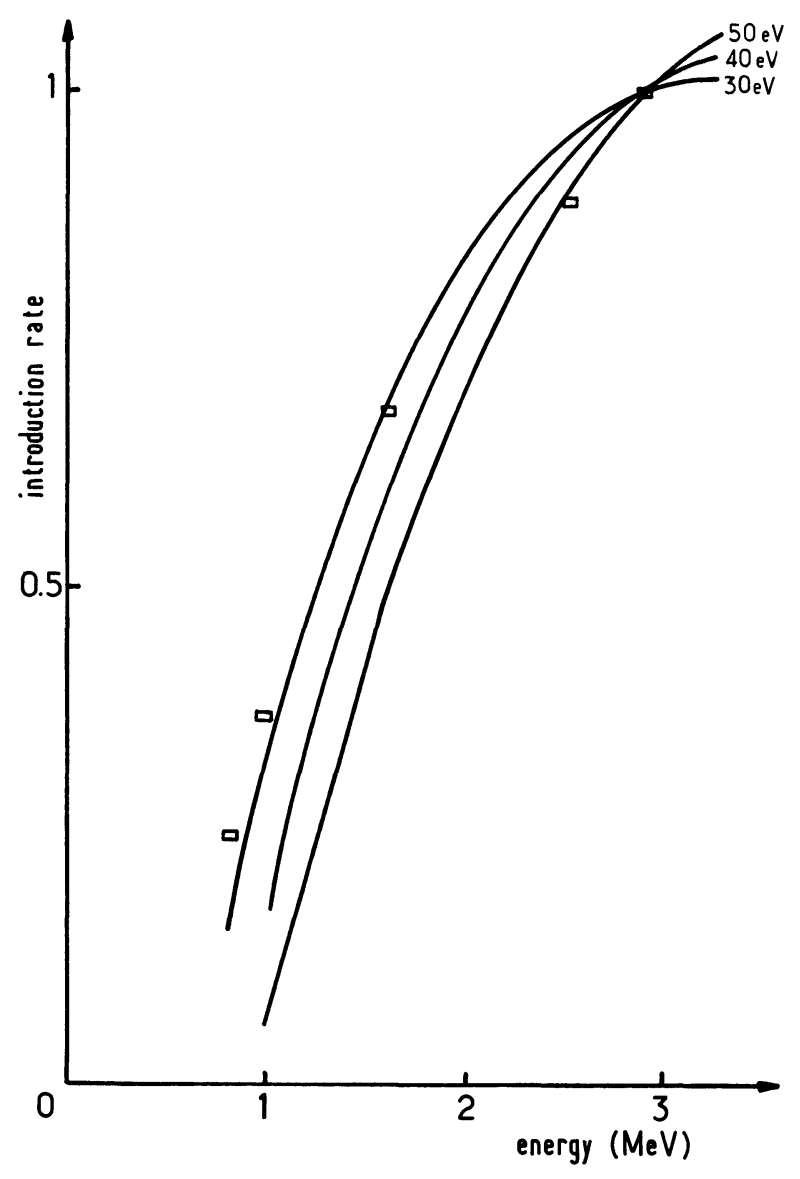

Fig. 5. - Variation of the $E_{4}$ trap introduction rate, normalized at $2.9 \mathrm{MeV}$, versus electron energy and comparison with theoretical curves calculated for various threshold energies.

to interstitial mobility [8]. Moreover, infrared absorption experiments suggest that the vacancy becomes mobile around $100 \mathrm{~K}$ [9]. Consequently $E_{1}$ and $E_{2}$ are associated to complexes, association of a vacancy, or of an interstitial, with an impurity. This conclusion is consistent with the fact that the introduction rate of the $E_{2}$ trap increases with the doping concentration [1]; then the impurity involved in the $E_{2}$ complex should be the doping impurity.

Divacancies are also probably created by the association of two mobile vacancies. However, except for low energies of irradiation, the concentration of divacancies created directly, i.e. by the displacement of two neighbouring atoms, should be larger.

The traps $E_{4}$ and $E_{5}$ are associated with defects which exhibit a threshold at $40 \pm 10 \mathrm{eV}$, i.e. $\sim 2 T d$. This suggests strongly that, like in silicon, these defects involve the divacancy. If the divacancy is not mobile at room temperature, $E_{4}$ and $E_{5}$ should be both associated with the divacancy. In that case both traps would be in equal concentrations since the Fermi level is well above the trap levels (at $\sim E_{\mathrm{c}}-0.26 \mathrm{eV}$ ). Table 1 indicates that the concentrations $N_{\mathrm{T} 4}$ and

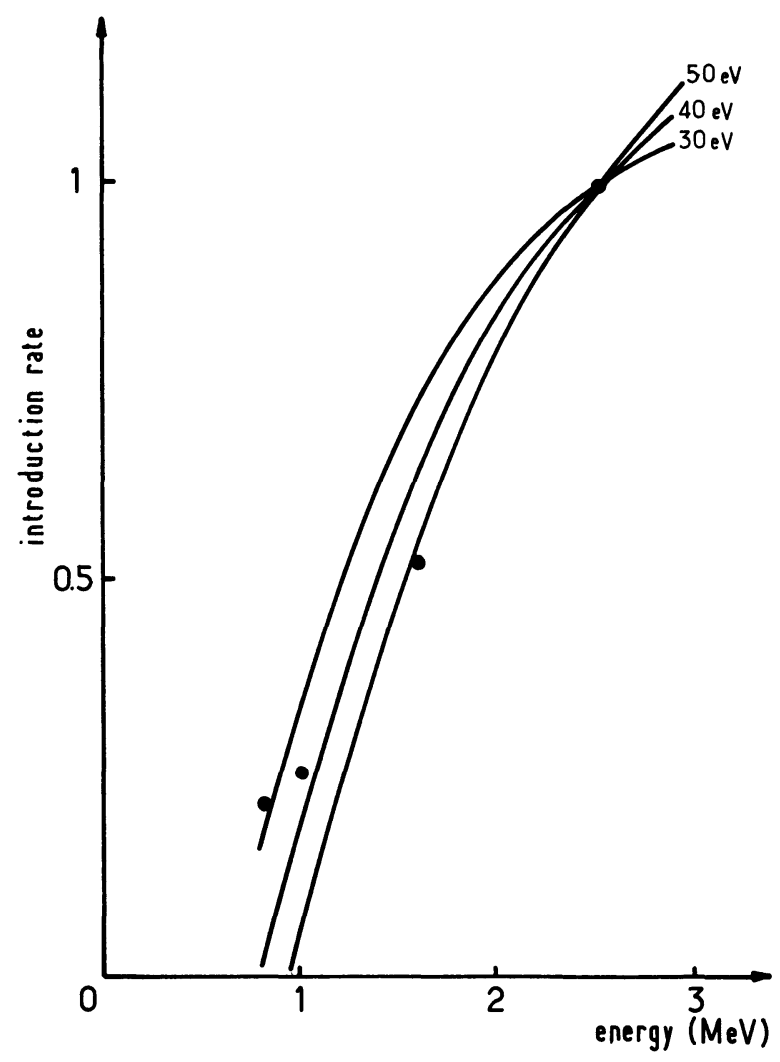

Fig. 6. - Variation of the $E_{5}$ trap introduction rate, normalized at $2.5 \mathrm{MeV}$, versus electron energy and comparison with theoretical curves calculated for various threshold energies.

$N_{\text {T5 }}$ are equal for diodes 10 and 19 , in which the traps $E_{4}$ and $E_{5}$ are correctly resolved. For other diodes, in which $E_{4}$ and $E_{5}$ are poorly resolved, their concentrations are still equal within the experimental error (which is of the order of $50 \%$ for diodes 16, 17 and 12 and reaches $100 \%$ for diodes 9,13 and 7). The traps $E_{4}$ and $E_{5}$ are therefore, most probably, present in equal concentration. We can then conclude that the levels $E_{4}$ and $E_{5}$ can be attributed to the divacancy, stable at room temperature.

5. Conclusion. - From the study of the variation, with the energy of irradiation, of the introduction rates of the four majority carrier traps we observed in electron irradiated n-type germanium, we have obtained the threshold energies for atomic displacement associated with these traps. Because two of the traps $\left(E_{4}\right.$ and $\left.E_{5}\right)$ exhibit a threshold energy about two times the threshold energy of the two other traps $\left(E_{1}\right.$ and $\left.E_{2}\right)$ we concluded that the $E_{1}$ and $E_{2}$ traps are associated with complex defects involving the association of a vacancy or of an interstitial with impurities while the traps $E_{4}$ and $E_{5}$ are associated with the divacancy. These two majority carrier trapping levels of the divacancy are situated at 0.32 and $0.35 \mathrm{eV}$ from the conduction band. 


\section{References}

[1] Mooney, P. M., Cherki, M. and Bourgoin, J. C., J. PhysiqueLett. 40 (1979) L-19.

[2] Lang, D. V., J. Appl. Phys. 45 (1974) 3023.

[3] Corbett, J. W. and Watkins, G. D., Phys. Rev. 138 (1965)

$$
\text { A } 555 \text {. }
$$

[4] Pons, D., Thesis (University Paris 6, 1979).

[5] Bourgoin, J. C., Ludeau, P., Massarani, B., Revue Phys. Appl. 11 (1976) 279.

[6] The references can be found in CorbetT, J. W. and Bourgoin,
J. C. in Point Defects in Solids, ed. J. H. Crawford and L. M. Slifkin (Plenum Press, New York) vol. 2 (1975) chap. 1.

[7] Mackkay, J. W. and Klontz, E. E., J. Appl. Phys. 30 (1959) 1269.

[8] Bourgorn, J. C. and Mollot, F., Phys. Status Solidi (b) 43 (1971) 343

[9] Whan, R. E., Phys. Rev. 140 (1965) A 690. 